\title{
A Common Ground: Communication and Alliance between Cataloguer and Curator for Improved Access to Rare Books and Special Collections
}

\author{
Elaine Beckley Bradshaw and Stephen C. Wagner
}

\begin{abstract}
Rare book catalogers and special collections curators can benefit greatly from cooperating on matters concerning cataloging policy and practice. This alliance is necessary for providing full access to special collections in a rapidly changing library environment. The authors examine rare book cataloging from the perspectives of cataloger and curator; discuss the areas where a cataloger-curator alliance can affect cataloging, as well as relevant factors over which the two have little control; and promote a concept of customized cataloging for special collections materials.
\end{abstract}

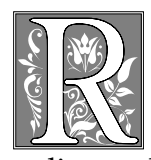

are book catalogers and special collections curators can benefit greatly from cooperating on matters concerning cataloging policy and practice. Indeed, such an alliance is necessary for providing full access to special collections materials in an environment that is changing rapidly and perhaps insensitive to standards and practices of special collections librarianship. This article examines rare book cataloging from the perspectives of both cataloger and curator. The authors discuss the areas where a cataloger-curator alliance can affect policies and decisions, as well as the factors over which such an alliance has little control but which, nevertheless, need to be taken into account. Collaboration between catalogers and curators is just as important as that between curators and conservators, donors, administrators, and researchers. ${ }^{1}$
The curator benefits from rare book cataloging by gaining better intellectual control over the collections' holdings, thereby promoting more effective reference, collection development, and outreach. However, to take advantage of its benefits, the curator first must know the basics of rare book cataloging, regardless of whether he or she ever catalogs a book. ${ }^{2}$ More specifically, the curator must be able to read, understand, and recognize the limitations of records in the local online catalog, OCLC and/or RLIN, and other libraries' online catalogs accessible via the Internet. The curator who understands the language of cataloging can expect to have a more profitable relationship with not only the rare book cataloger but also the cataloging department as a whole. Finally, a curator writing any grant proposal whose aim is to improve intellectual access to the collections, including the

Elaine Beckley Bradshaw is the Cataloging/Computer Services Librarian in the University of Oklahoma Law Library; e-mail: ebradshaw@ou.edu. Stephen C. Wagner is the History of Science Bibliographer in the Department of Philosophy at the University of Oklahoma; e-mail: swagner@ou.edu. 
construction of indexes and databases, must demonstrate and incorporate knowledge of the fundamentals of rare book cataloging. ${ }^{3} \mathrm{He}$ or she will have an even greater need for knowledge of rare book cataloging when supervising a cataloger either on staff or as part of a grant project.

\section{In special collections, outsourcing is useful only for a very limited range of materials.}

In turn, the cataloger benefits from knowledge of the collections' strengths and overall mission. This knowledge, combined with an idea of the research needs of the collections' patrons, enables the cataloger to customize certain elements of the cataloging record to better serve the needs of the collections and their users. Moreover, the cataloger should be aware of any backlogs or otherwise inaccessible materials held by the collections, the nature of the backlog (e.g., its size, subject matter(s), range of dates of publication), and any priorities the curator has regarding cataloging. This is an example where cooperation between cataloger and curator may bring about effective policy - in this case, for cataloging a back$\log$.

In this article, the authors elaborate on the themes of communication and alliance in terms of goals and constraints. By goals, the authors mean informed decision making and subsequent action where cataloger and curator can set policy, establish procedures, and achieve optimal access to special collections materials. By constraints, they mean factors, large and small, over which curator and cataloger have little control. Thus, goals concern the ultimate aim of access and how best to achieve it, and constraints can restrict any action taken by curator and cataloger and are, to a certain extent, constituted by the institutional environment in which rare book catalogers and special collections curators toil. Both also operate within a broader professional culture, as discussed in the following sections.

\section{Current Trends in Librarianship}

Several recent trends in librarianship, general as well as specific, undermine both traditional cataloging practice and the needs of special collections. ${ }^{4}$ For example, in-house cataloging departments at some institutions are under attack by library administrators who emphasize cost cutting and believe that these departments are too expensive. In all libraries, cataloging departments are under fiscal scrutiny and present easy behind-thescenes targets for cutbacks. Similarly, special collections appear to be ancillary to many libraries' self-proclaimed missions in a developing information age. ${ }^{5}$ With such emphasis on their holdings and on a special facility for preservation and controlled access, special collections departments seem wildly out of step in a world of "libraries without walls" and the vision of libraries as networked information gateways. Thus, special collections departments, which also are expensive to administer, likewise are easy targets for cutbacks.

One specific trend is the outsourcing of cataloging. Although useful in circumstances where highly specialized materials require competencies outside the scope of many cataloging departments (e.g., formats such as sound recordings or languages such as Arabic), in other cases outsourcing is used merely as a blanket cost-cutting measure. In extreme cases, entire cataloging departments have been eliminated in favor of outsourcing. In special collections, outsourcing is useful only for a very limited range of materials. Even drawing up the profile for adequate cataloging is highly labor-intensive, as is reviewing cataloging records and making any in-house enhancement of inadequate records. Moreover, for preservation and security reasons, most curators would never consider sending special collections materials outside the library. Finally, as discussed below, the benefits of more customized cataloging will be realized only with the close in-house collaboration of cataloger with curator and with the materials always on hand. 
A second specific trend is that of minimal cataloging. This may include briefer cataloging records with limited description, little or no subject analysis, and few (if any) local notes or content notes. This trend flies in the face of the standards of rare book cataloging and the mission of special collections as resources for research and scholarship. For example, rare book cataloging standards demand more-not less-description, including full transcription of almost all title page information. Moreover, the customized cataloging advocated by the authors of this article emphasizes careful subject analysis and appropriate, more extensive use of notes (especially content and local notes) and added entries. Furthermore, in an era of reduced travel budgets and networked online library catalogs, scholars are becoming more-not less-dependent on fuller cataloging records.

Another general trend is the impact on libraries of evolving technologies. Although often beneficial, technological development seems to encourage many librarians, especially administrators and educators, to overestimate its use and effectiveness. Specifically, many retrospective conversions of card catalogs into online systems have fallen short of the ideal due to unrealistic estimates of the cost and labor involved. ${ }^{6}$ And despite the best intentions to thoroughly update all online records to current standards, nobody has had the time and resources to do so. In fact, the motivation behind retrospective projects is a rapid and straightforward conversion of the card catalog into a new, very useful format. Unfortunately, such a "quick and dirty" approach only glosses over the complexities of transforming a catalog historically assembled using cataloging standards that themselves have evolved significantly over time. Although this mix of cataloging standards has existed within card catalogs as well, the labeled displays of many online systems nevertheless mask the catalog's historical nature. Moreover, patrons may well assume that a new online system, like most new databases they have encountered, has been assembled from a single, consistent standard.

For a special collections setting, the situation is even worse. Not only do retrospective conversions typically work from existing, often brief, cataloging cards and not the actual item (either straight data input from the existing cataloging card or a match to an existing OCLC record), but they also rarely allow for cataloging to current rare book standards, which requires much additional time, research, and expertise. In effect, this means re-cataloging the rare books, a process that runs counter to the goal of relatively inexpensive retrospective conversion.

Another specific outcome of evolving technologies is their impact on the creation, distribution, preservation, and long-term access to electronic sources. One example is the availability of electronic journals and reference works, which to date has had little immediate impact on special collections and their holdings. However, in time, electronic sources may well fall within the scope of the collections. Often very little thought is given to considerations at the core of special collections librarianship: preservation and long-term access. Will these sources later be accessible at all or available in a format that ensures their longterm accessibility? Who will own these sources and have the rights for distribution and redistribution over time? Who will have responsibility for maintaining the data in an accessible format? Given the instability of storage media for electronic data, how will this responsibility be met? ${ }^{7}$ If, due to technical considerations, electronic resources are not "stored" physically in the collections, how will the goal of long-term access be met? Will a library or institution's systems office recognize, respect, fulfill, and give adequate priority to such a goal? These problems face libraries now without obvious resolutions, and they will have an even greater impact on special collections and cataloging in the future.

Another issue is that of making current holdings more broadly available 
through digitization and networked access. ${ }^{8}$ Whether such efforts will be effective for more than limited, well-defined subsets of special collections is unclear. In a library's world of limited resources, any such efforts take time, staff, and money away from basic library functions, including cataloging. 9 (Ironically, cataloging is the traditional library function most concerned with access.) Even worse, many repositories (such as smaller historical societies) that hold valuable, unique items (especially archives and manuscripts) do not have the resources to shift around to large-scale digitizing efforts. Grant-funded projects, even large ones, can achieve only limited goals. Even if the resources were available to digitize and index every item within a special collection, certain physical evidence necessary for scholarship (e.g., illustrations, watermarks, typefaces, the book's structure and binding) is available only with direct examination of the original item or, if possible, at an incredible investment of time and money. In place of these global digitalizing efforts, the authors see technology as complementing, not replacing, traditional library practices and extending the reach of special collections. ${ }^{10}$

On a positive note, some general trends in librarianship have advanced the cause of rare book cataloging. As a specific example, libraries have benefited in many ways from national cooperative efforts. The development of the international bibliographic utilities, OCLC and RLIN, has contributed to both cataloging and reference. The ability to download and modify bibliographic records has eliminated the need for each library to catalog every book from scratch, including rare books. Even though many online records lack the full detail demanded by an individual library's standards, online records still provide a timesaving template for enhancement. Moreover, these bibliographic utilities provide records and holdings data that support better reference and collection development. All of these benefits accrue to special collections.
However, cooperative efforts fall flat unless they are based on an accepted set of standards. ${ }^{11}$ Online bibliographic records would be far less accessible without cataloging standards such as AACR2. With regard to rare books, the manual Descriptive Cataloging of Rare Books (DCRB) supplements $A A C R 2$ by permitting fuller descriptive cataloging appropriate to rare books. ${ }^{12}$ DCRB also provides an effective tool for training the rare book cataloger. Other standards, such as the Library of Congress Subject Headings (LCSH) and the LC name authority file, benefit the rare book cataloger as well.

Technology also has brought benefits. First and foremost, it provides access to this wealth of information on the bibliographic utilities. Moreover, access to other libraries' online catalogs via telnet, and now the World Wide Web has been a benefit for cataloging and reference. For cataloging, these benefits include noting how other catalogers have emended and expanded the minimal record available through OCLC or RLIN in terms of enhancement of descriptive elements, use of special thesaurus terms (e.g., for binding or provenance), and assignment of subject headings. For reference, benefits include more user-friendly searching, the ability to do special searches (such as browse the call number range of a particular, rich collection), enhanced subject searching, the use of fuller cataloging records to identify specific texts and their editions, and the potential to track acquisitions at other collections to enhance one's own collection development efforts. These factors apply especially to searching the catalog of large, well-known, and well-managed collections in similar or related subject areas.

More general benefits for both catalogers and curators include networking through listservs and e-mail; the availability of resources on the Web (such as foreign-language dictionaries, cataloging tools, and special collections project reports); a reduced sense of isolation, even for those working at larger research 
libraries; the promotion of large- and small-scale cooperative efforts, both formal and informal; and the promotion, development, and refinement of standards.

\section{Ideals and Reality}

Of course, the primary issue is the quality of the catalog-for catalogers, curators, patrons, and others. The quality of the catalog can be defined in terms of:

- the quality of the individual cataloging records, including detail, accuracy, and relevance of access points to the collection, institution, and their patrons;

- the incorporation of relevant authority control;

- its comprehensiveness (i.e., its reflection of the collection's overall holdings);

- its accessibility, especially online access via the Internet;

- the characteristics of the on-line system, in terms of both searching and display.

In addition to the benefits listed above for cataloging and reference, an outstanding online catalog can benefit individuals and institutions outside the facility. For example, scholars regularly send e-mail messages to the History of Science Collections at the University of Oklahoma Libraries that include downloaded cataloging records from its online system. If the catalog were more comprehensive and more completely done to rare book cataloging standards, another scholar or institution's request for information on the collection's holdings could be handled more easily. Moreover, rare book dealers could make use of a comprehensive, detailed online catalog when helping the History of Science Collections develop its rare book holdings. In a similar vein, the curator would benefit immeasurably from having Internet access to a complete catalog when on book-buying trips to Europe, thereby helping reduce the returns of duplicate items.

However, even realized ideals are achieved within real-world constraints. Such constraints may be internal (i.e., the institution or the collection) or external (e.g., national and international standards, cooperative agreements).

The primary institutional constraint is budget. The largest budget item for most libraries is staff salary, which translates into time spent working. For a library administration concerned with limiting spending in a era of slow growth or even cutbacks, assigning staff to the highly labor-intensive effort of rare book cataloging, which benefits only a small portion of the overall library's holdings and patron use, may seem problematic. Putting this money and time into reference, automation, and acquisitions-or even clearing the omnipresent cataloging backlogoften seems to be a better use of limited resources. Even within a special collection, clearing a backlog and providing at least minimal access to the entire holding may be deemed more important than providing a detailed cataloging record for every item sometime in the distant future. In other words, one ideal (access to the entire collection) may be in conflict with another ideal (full, detailed cataloging records).

\section{The need for cooperation in rare book cataloging simply may not be recognized, however obvious it may seem on the face of it.}

On the other hand, cataloging special collections materials simply demands more time and effort to do well than other types of cataloging. It also enhances local reference while simultaneously contributing to the scholarly community, a goal of any research library or any institution housing a major special collection. Institutions that are willing to accept a special collection and benefit from the prestige of such holdings also acquire a responsibility that extends beyond the mere housing of materials to their preservation and access.

A second institutional constraint is staffing. Staffing is more than a budgetary consideration. Rare book cataloging demands expertise and training beyond 
what is required in most cataloging departments, even those that do a significant amount of original cataloging. The authors' emphasis on cooperation between catalogers and curators dictates both rare book-cataloging skills from the cataloger and subject knowledge from the curator.

A third institutional constraint is administrative organization. When special collections are part of public services and cataloging is part of technical services (a common library administrative structure), opportunities for collaboration are hindered. The need for cooperation in rare book cataloging simply may not be recognized, however obvious it may seem on the face of it. Similarly, the benefits are not discerned or articulated without ongoing discussion at all levels of the library. Nevertheless, the benefits strongly outweigh the costs of establishing connections across administrative lines.

One alternative is to place the rare book cataloger within special collections. Opportunities for collaboration are enhanced because regular discussion between cataloger and curator is accomplished more easily. Communication is only the first step; specific policies and procedures remain to be developed. However, enhanced communication is a necessary first stage in identifying and addressing issues that lead to effective cataloging and hence to access to collections' materials.

A fourth constraint is the requirement of libraries to meet accepted cataloging standards. The benefits of large-scale cooperation and the need for standards were discussed above. At the institutional level, though, those benefits come at a cost-namely, the obligation to adopt only what the standards dictate. For descriptive cataloging, such drawbacks can be minimized with $D C R B$ and the wise use of notes fields. However, subject and name access may be inadequate for local needs. In such cases, one either concedes the loss or creates two records, one for the national utilities and one for the local catalog, but only at the cost of additional time.

\section{Customized Cataloging}

Driven by the ideal of a high-quality catalog and the above-mentioned constraints, cataloger and curator must resolve several matters of policy and practice in working toward the optimal balance of timely access and detailed records. The following issues should be discussed well before any cataloging is done:

- Will priorities be assigned to materials needing cataloging, or will books be done on a "first-in, first-out" basis?

- What is the most appropriate level of cataloging for the collections? Do different parts of the collections get cataloged to different degrees of detail?

- What cataloging standard should be used: $A A C R 2$ or DCRB?

- Most important, what records will be customized for the collections, and in what ways?

- How can characteristics of the online system be made to reflect fully the results of optimal cataloging?

It is precisely collaboration on these policy and practice issues that leads to what the authors referred to at the beginning of this article as customized cataloging - that is, using a combination of subject knowledge and cataloging acumen to customize the catalog to provide an optimal match between the records in the catalog and the items in the collections. The rest of this article elaborates on this concept.

To integrate cataloging with other special collections' functions, the curator needs to articulate cataloging priorities. Establishing priorities relies on his or her knowledge of the collections and their use. Ultimately, the curator's decisions depend on the following criteria: acknowledgment, subject, time period, and value. Acknowledging gifts and purchases from special funds via prompt cataloging provides proper recognition of welcome support of any special collections, recognition that does not accrue to items buried in a backlog. Cataloging can encourage better utilization of the collections by focusing on subject strengths or past, current, and anticipated use (e.g., 
new faculty or visiting scholars). Priorities also may be based on time period (e.g., incunables) or value (monetary or scholarly). There is no ready-made formula for balancing these criteria; rather, decisions must be made based on judgment and knowledge of the collections.

Deciding what to do with a substantial backlog further complicates the process of setting cataloging priorities. As mentioned above, cataloging a backlog pits one ideal (access to the entire collections) against another (detailed bibliographic records for each item in the collections). The authors believe that the wisest course is to build slowly and steadily a high-quality catalog rather than face the possibility of either cataloging every item twice or never cataloging materials to rare book standards.

Before specifying appropriate cataloging standards and levels of description, three assumptions must be mentioned. First, for security reasons, some type of record needs to be made for every item as it enters the collections. For example, in the History of Science Collections at the University of Oklahoma Libraries, a temporary record for all incoming materials is created in both the card catalog and the short-title database. This provides two independent, complete lists of the collections' holdings. More generally, in an age of integrated library systems, the authors envision simply having minimal cataloging records linked to order records (to include both orders and gifts). Second, discussion should be limited to the cataloging of books and issues concerning archives and manuscripts should be left aside. Third, currently published secondary sources should receive adequate cataloging as they pass routinely from acquisitions through centralized cataloging to the special collections.

The next question to deal with concerns the amount of detail to provide in the process of cataloging. This in turn divides into several categories: descriptive cataloging, subject analysis, classification, authority work, and added entries.
Descriptive cataloging reveals a continuum of detail from remarkably sparse (e.g., a minimal $A A C R 2$ record) to incredibly elaborate (e.g., full $D C R B$ ). The authors propose the following recommendations, subject to modification by the curator and cataloger:

1. A minimal $A A C R 2 R e v$ record for all incoming materials: This record is recommended above for security reasons to be linked with an order/gift record.

2. A full AACR2Rev record for currently published materials (as mentioned above) and nineteenth and twentieth machine-press book: In conjunction with the curator, the cataloger may decide to include extra notes (such as notes on signature, advertisements, errata, physical details of multivolume sets) for books whose importance and/or structure so requires. ${ }^{13}$ Curator and cataloger may decide to follow $D C R B$ in certain cases when greater descriptive detail demands it.

3. A full DCRB record for all hand-press books and some machine-press books: DCRB more fully and accurately describes the book, allowing a complete and unaltered transcription of the title page and recording the physical structure of the book (format, signatures, pagination, illustrations). ${ }^{14}$ This level of detail is useful for reference, security, collection development, cataloging, and scholarly purposes.

Concerning the last recommendation above, even within $D C R B$, there are several options for varying levels of detail. ${ }^{15}$ For example, the title page punctuation may be retained in addition to the required ISBD punctuation, thereby resulting in "double punctuation." The cataloger can convert a date appearing in roman numerals on the title page to Arabic numerals or transcribe the date in both roman and Arabic numerals (the latter within square brackets). In the physical description area, the cataloger can record both the specific type of illustration (e.g., map, plan, portrait) and the technique of illustration (e.g., woodcut, copper plate engraving), if either is deemed significant.

However, the greatest opportunity for customization exists within the notes- 
area. Beyond the three mandatory note types in DCRB (giving source of title, edition, or publication information taken from outside the chief source; indicating transposition of title page elements; and noting errata leaves or slips), there is a wide range of options including, but not limited to, notes on title variations, authorship, edition and bibliographic history, publication, signatures, physical description, references to published descriptions, and contents.

In addition to these universal notes, the cataloger and the curator also may decide to include a variety of local or copy-specific notes. They may decide to use local notes for a variety of situations, including imperfect copies, extra illustrated or interleaved copies, binding, hand-colored illustrations, annotations, provenance, and some bound-withs. Local notes may be used to support added entries for names, titles, genre/forms, physical characteristics, and provenance but are not required by $D C R B$.

Having agreed on appropriate levels and standards for descriptive cataloging, the cataloger and the curator may even wish to establish an item-by-item review of cataloging records for issues that depend on detailed subject knowledge: subject analysis, classification, authority work, and additional access points. In these cases, the curator's subject knowledge, knowledge of the current literature in the field, and knowledge of the history of books and printing will prove valuable assets for comprehensive, accurate cataloging.

Concerning subject knowledge, a curator-cataloger collaboration may decide, for original cataloging, not to place restrictions on the appropriate number of subject headings (e.g, beyond the common practice of three to five subject headings per book) as well as allow for headings in books of a more encyclopedic nature that may contain small, but highly important, sections on a given subject (i.e., opting for many specific headings instead of one general heading). For copy cataloging, including twentieth-century books, the two may make similar decisions when the historical importance of a work or its anticipated use dictates more detailed subject headings. As a corollary, curator and cataloger may decide to reclassify a work to better match the current holdings or use of the collections.

Concerning authority work, the curator occasionally may identify the need to revise an authority record (e.g., an undifferentiated personal name). Beyond this, however, the curator may have a different goal in mind: to provide as much information about an author as possible, as opposed to providing only enough information to distinguish one author from another. To this end, the curator may want to work with the cataloger to enhance authority records in the local system by adding, for example, a complete set of birth and death dates or a cross-reference to a different or fuller form of name.

Finally, cataloger and curator will want to collaborate on additional access points. For example, they may decide for works such as conference proceedings to add names of prominent contributors who did not appear in the initial cataloging record. Depending on the collections and their use, they may add names of illustrators, engravers, binders, printers, and publishers. Moreover, they may determine the need for a uniform title to collocate books with a long printing history (e.g., Euclid's Elements). Lastly, they may wish to add terms to a cataloging record that formerly were included in special card files for topics such as paper, type, binding, printing and publishing, and provenance. ${ }^{17}$

However, all of this work toward providing a comprehensive, accurate set of cataloging records will be for naught if the local system cannot adequately display all the information packed into the records. What the patron sees in the catalog display is constrained by national standards, local system limitations, and local decisions concerning what to display and how. The alliance of curator and rare book cataloger provides essential input into the selection of an integrated library system and its adaptation for local usage. Because of 
the peculiar characteristics of rare book cataloging records, only these two individuals will have the knowledge for, and interest in, promoting a display adequate for reference and scholarship. Due to the administrative structure of most libraries, the alliance will be able to voice these concerns in both public services and technical services meetings.

The concerns are really twofold: (1) the ability to search effectively throughout all relevant elements of the record, and (2) the capability to have displayed all relevant information within each record. Especially important are full title, physical characteristics and other nontextual elements, notes, and relator terms. For title, the system itself should not arbitrarily truncate the title after a given number of characters. For physical and other nontextual characteristics, the online cata$\log$ should be able to mimic the special card files of old for topics such as paper, type, binding, printing and publishing, and provenance. For notes, systems should have the option of displaying and searching all notes fields, including local notes (e.g., additional information on provenance, binding, or condition). Finally, for relator terms, the system should be able to support records with such terms, which are used to distinguish name headings (e.g., to list separately an individual as author, previous owner, dedicatee, printer, illustrator, forger). Only with the prompting of cataloger and curator will the results of customized cataloging be displayed consistently and available for scholars. ${ }^{18}$

\section{Conclusion}

Open lines of communication between cataloger and curator can make the most of the limited time a rare book cataloger may have to work with the collection. A cataloging strategy, worked out in advance and drawing on the knowledge and skills of both cataloger and curator, can assure that high-priority items receive the full attention of the cataloger and are made accessible as soon as possible. Working together and keeping in mind the needs and character of the collection, together they can identify materials needing the most detailed cataloging, as well as items for which briefer records may be appropriate. Based on an effective collaboration between cataloger and curator, customized cataloging can provide maximum access to special collections materials, to the benefit of all.

Customized cataloging begins with an examination of every element of a cataloging record in order to make it as faithful a representation of the work as possible. Ultimately, customized cataloging ends with the fullest use possible of the collections for scholarship and teaching.

\section{Notes}

1. For example, Cathy Henderson, "Curator or Conservator: Who Decides on What Treatment?" in Rare Books E Manuscripts Librarianship 2 (fall 1987): 103-7 or Roberta Pilatte and Carolyn Harris, "It Takes Two to Tango: A Conservator's View of Curator/Conservator Relations," in Rare Books \& Manuscripts Librarianship 4 (fall 1989): 103-11.

2. That such a need exists is recognized by the addition of the course "Rare Book Cataloging for Curators" in the summer 1998 offerings at Rare Book School, University of Virginia.

3. For example, one recent project in the History of Science Collections, University of Oklahoma Libraries, was to catalog a large (c. 20,000-item) slide collection onto a Microsoft Access database. The original database structure, developed by historians without collaboration with librarians, would at best have been a stand-alone, in-house system. The collaboration of a rare book librarian, a cataloger, and a library systems person resulted in a revamped database whose structure would readily map into a MARC format and whose entries into data fields would use the appropriate controlled vocabularies (e.g., LCSH). The database now can be converted into a MARC database compatible with the local OPAC, a feature that eventually will make the database much more accessible and more easily searched.

4. Suzy Taraba, "Administering the Cataloging of Special Collections Materials," in Rare Books and Manuscripts Librarianship 7 (1992): 87-90.

5. For an alternate vision, see Peter S. Graham, "New Roles for Special Collections on the 
Network," in College \& Research Libraries 59 (Mar. 1998): 232-39.

6. Nicholson Baker, "Discards," New Yorker, 4 Apr. 1994, 64-86. See also Henry L. Snyder, "Providing Access to Rare Book and Manuscripts Collections and Services in a Time of Change: The Electronic Revolution," in IFLA Journal 22 (May 1996): 115-20.

7. Jeff Rothenberg, "Ensuring the Longevity of Digital Documents," in Scientific American 272 (Jan. 1995): 42-47.

8. Examples include the Tobacco Control Archives, University of California at San Francisco (http:/ / www.library.ucsf.edu/tobacco/); the Human Radiation Experiments site, U.S. Department of Energy (http://tis-nt.eh.doe.gov/ohre/); the Digital Scriptorium, Duke University (http:// scriptorium.lib.duke.edu/); and the Electronic Text Center, University of Virginia (http:// etext.lib.virginia.edu/).

9. Some libraries have indeed shifted most of the resources for their electronic libraries from their cataloging departments.

10. The authors currently are examining ways that digitized images can enhance work done in rare book cataloging and descriptive bibliography. A parallel project of a professor of the history of science is to scan and convert text from historical sources.

11. John B. Thomas III, "The Necessity of Standards on an Automated Environment," in $\mathrm{Li}$ brary Trends 36 (summer 1987): 125-39.

12. Descriptive Cataloging of Rare Books, 2nd ed. (Washington, D.C.: Library of Congress, 1991).

13. It is useful for some machine-press books to include signatures, which can help identify different printings. For multivolume sets, notes can describe pagination of individual volumes, plates, dates of publications, and variant publishers. This is especially important for made-up sets.

14. Laura Stalker and Jackie M. Dooley, "Descriptive Cataloging and Rare Books," in Rare Books and Manuscripts Librarianship 7 (1992): 7-23.

15. An example of this is the Core Standard for Rare Books (DCRB Core) (http://lcweb.loc.gov/ catdir/pcc/dcrbcore.html).

16. DCRB, 54-65, note 12 .

17. The authors have in mind topics covered by the RBMS thesauri for binding, genre, paper, printing and publishing, provenance, and type.

18. For a fuller and more technical discussion of these points, see Henry Raine and Laura Striker, "Rare Book Records in Online Systems," in Rare Books and Manuscripts Librarianship 11 (1996): 103-18. See also the Guide to Rare Book Records in Online Systems (http:/ / www.lib.byu.edu / $\sim$ catalog/people/rlm/bsc/guide.htm). 